\title{
Time to revise the paradigm of hantavirus syndromes? Hantavirus pulmonary syndrome caused by European hantavirus
}

\author{
J. Rasmuson • C. Andersson • E. Norrman • M. Haney • \\ M. Evander • C. Ahlm
}

Received: 2 September 2010 /Accepted: 20 December 2010 /Published online: 15 January 2011

(C) The Author(s) 2011. This article is published with open access at Springerlink.com

\begin{abstract}
Hantaviruses have previously been recognised to cause two separate syndromes: hemorrhagic fever with renal syndrome in Eurasia, and hantavirus pulmonary syndrome (HPS) in the Americas. However, increasing evidence suggests that this dichotomy is no longer fruitful when recognising human hantavirus disease and understanding the pathogenesis. Herein are presented three cases of severe European Puumala hantavirus infection that meet the HPS case definition. The clinical and pathological findings were similar to those found in American hantavirus patients. Consequently, hantavirus infection should be considered as a cause of acute respiratory distress in all endemic areas worldwide.
\end{abstract}

J. Rasmuson $(\bowtie) \cdot$ C. Ahlm

Infectious Diseases, Department of Clinical Microbiology,

Umeå University,

SE - 90185 Umeå, Sweden

e-mail: johan.rasmuson@climi.umu.se

C. Andersson

Pathology and Cytology, Department of Medical Biosciences,

Umeå University,

Umeå, Sweden

E. Norrman

Respiratory Medicine, Department of Public Health and Clinical

Medicine, Umeå University,

Umeå, Sweden

M. Haney

Anesthesia and Intensive Care Medicine, Department of Surgery and Perioperative Sciences, Umeå University,

Umeå, Sweden

M. Evander

Virology, Department of Clinical Microbiology, Umeå University,

Umeå, Sweden

\section{Introduction}

The present paradigm is that hantaviruses in the Americas cause hantavirus pulmonary syndrome (HPS), while hemorrhagic fever with renal syndrome (HFRS) is caused by hantaviruses present in Eurasia [1-3]. Hantaviruses associated with HFRS and HPS are primarily transmitted by inhalation of viral particles shed by infected rodents $[4,5]$. In both syndromes there is a local immune reaction in the lungs, mainly in terms of a $\mathrm{CD}^{+} \mathrm{T}$ lymphocyte response $[2,6,7]$. Another important feature is endothelial dysfunction and capillary leakage $[1-3,8]$. After the prodromal phase, including fever, nausea, myalgia and headache, patients with HFRS commonly develop renal failure whereas in HPS the kidneys are often spared and instead the patient frequently presents with severe cardiopulmonary dysfunction $[1,3,9]$.

Although usually less severe and sometimes overlooked, pulmonary symptoms are common in European HFRS caused by Puumala virus (PUUV). Frequent clinical findings include cough, dyspnoea, interstitial lung infiltrates, pleural effusion and impaired pulmonary function [10-12]. Pronounced lung involvement in HFRS has previously been reported [13-16]. However, none of those reported patients had a fatal outcome that could be attributed to the acute infection, and there is no description of histopathological findings.

Our hypothesis is that also European hantaviruses can cause HPS. The aim of this study was to investigate whether HFRS patients with severe cardiopulmonary distress fulfil HPS criteria and have similar clinical and pathological features.

\section{Materials and methods}

In a prospective study, during the latest hantavirus outbreak in 2007 in the county of Västerbotten, Sweden [17], HFRS 
patients with cardiopulmonary failure and need of invasive assisted ventilation, i.e. intubation and mechanical ventilation, were selected. We identified three patients, two of which had fatal outcome and one survived. The two patients who died both underwent autopsy three days post-mortem. Organ samples were investigated using immunohistochemistry to describe the immunological response and detect presence of viral antigen. Quantitative real-time RT-PCR was used to detect viral RNA in organ samples, plasma and bronchoalveolar lavage [18].

For defining HPS we used the case definition criteria published by the U.S. Centers for Disease Control and Prevention (CDC) [19]. The project was approved by the Research Ethics Committee of Umeå University. Informed consent was obtained either from the patient, or a close relative when not possible.

\section{Results}

\section{Patient 1}

A 73-year-old woman was admitted to the intensive care unit (ICU) with acute respiratory distress. She was a lifelong non-smoker living with her husband in a rural area, and had a medical history of hypertension and type II diabetes. The day prior to admission she fell ill with malaise and fever. Nausea, vomiting and pronounced shortness of breath ensued. The initial findings at admission included fever, tachycardia, tachypnoea, hypoxia and somnolence. Laboratory findings during hospitalisation indicated coagulopathy, elevated levels of lactate dehydrogenase (LDH), and development of renal failure (Table 1). There was release of cardiac enzyme troponin $\mathrm{T}$ (peak value 1.6; normal value $<0.01 \mu \mathrm{g} / \mathrm{L}$ ), indicating myocardial tissue damage.

Lung computer tomography (CT) on admission revealed pronounced diffuse bilateral interstitial infiltrates with pulmonary oedema, dependant atelectasis, and moderate pleural effusions (Fig. 1) which were later drained $(>800 \mathrm{ml})$. Echocardiography showed inferior hypokinesia, moderate mitral valve insufficiency, normal sized left ventricle and atrium, and systolic pulmonary arterial pressure estimated at $55 \mathrm{~mm} \mathrm{Hg}$. Despite non-invasive positive pressure respiratory support and furosemide, her respiratory distress progressed and she was intubated and mechanically ventilated on the first hospital day. The preliminary diagnosis was acute respiratory distress syndrome of uncertain cause, and she was treated with broad-spectrum antibiotics and corticosteroids without improvement. Vasopressor and inotropic support was required to maintain adequate circulation. Repeated echocardiogram showed no overt signs of cardiac failure, though several days into her illness the systolic pulmonary arterial pressure increased to $>65 \mathrm{~mm} \mathrm{Hg}$. Maximal inspiratory pressures $\left(40 \mathrm{~cm} \mathrm{H} \mathrm{H}_{2} \mathrm{O}\right)$ were required to maintain minimally adequate oxygenation. She suffered a pneumothorax, and received a large bore thoracostomy with negative pressure drainage. The patient developed multiple organ dysfunction engaging the central nervous, respiratory, cardiovascular, renal and coagulatory systems, and she died after 13 days of ICU care.

PUUV serology was initially negative, but seroconversion occurred during the first week with development of positive immunoglobulin $\mathrm{M}$ (IgM) and $\operatorname{IgG}$. No PUUV RNA could be detected in serum or bronchoalveolar lavage fluid, sampled two days after onset of disease. At autopsy PUUV RNA was detected in lung tissue, but not in samples from heart, brain, spleen and liver. Sequencing of the PUUV RNA from lung tissue showed that it was homologous to PUUV strains circulating in northern Sweden. No PUUV antigen could be detected in the tissue by immunohistochemistry using PUUV specific monoclonal antibody. Relevant bacterial cultures were all negative. Notably, three weeks prior to ICU admission the patient had sought medical treatment at our clinic for a urinary tract infection caused by E. coli. In the serum collected at that time PUUV RNA (1,700 copies/ml) was later detected.

Table 1 Laboratory findings in three European hantavirus patients suffering from hantavirus pulmonary syndrome

\begin{tabular}{|c|c|c|c|c|c|c|c|}
\hline Patient No., Sex/Age & $\mathrm{WBC}^{\mathrm{a}}$ & $\mathrm{TPC}^{\mathrm{b}}$ & $\mathrm{aPTT}^{\mathrm{a}}$ & $\mathrm{INR}^{\mathrm{a}}$ & Albumin $^{\mathrm{b}}$ & Creatinine $^{\mathrm{a}}$ & $\mathrm{LDH}^{\mathrm{a}}$ \\
\hline 1: F/73 y & $6.5 / 40.9$ & $293 / 42$ & $26.7 / 40.9$ & $1.2 / 1.9$ & $29 / 28$ & $50 / 234$ & $11.4 / 30.8$ \\
\hline 2: F/65 y & $15.5 / 50.3$ & $108 / 17$ & $49.9 />180.0$ & $1.4 / 1.9$ & $18 / 18$ & $87 / 171$ & $5.2 / 8.7$ \\
\hline 3: $\mathrm{M} / 63 \mathrm{y}$ & $12.4 / 23.0$ & $137 / 9$ & $42.0 / 80.0$ & $1.5 / 2.0$ & ND & $124 / 164$ & $21.2 / 21.2$ \\
\hline
\end{tabular}

WBC white blood cell count (normal range 3.5-8.8 $\times 10^{9} / \mathrm{L}$ ), TPC thrombocyte particle count (normal range for women 165-387 and for men 145$348 \times 10^{9} / \mathrm{L}$ ), aPTT activated partial thromboplastin time (normal range 24.0-36.0 seconds), INR international normalized ratio (normal range 0.8-1.2), serum albumin (normal range 36-45 g/L), serum creatinine (normal range for women 50-90 and for men 60-100 $\mu$ mol/L), $L D H$ lactate dehydrogenase (normal value $<3.4 \mu \mathrm{kat} / \mathrm{L}$ ), $N D$ no data

${ }^{\mathrm{a}}$ Initial and peak laboratory results, respectively

${ }^{\mathrm{b}}$ Initial and nadir laboratory results, respectively 


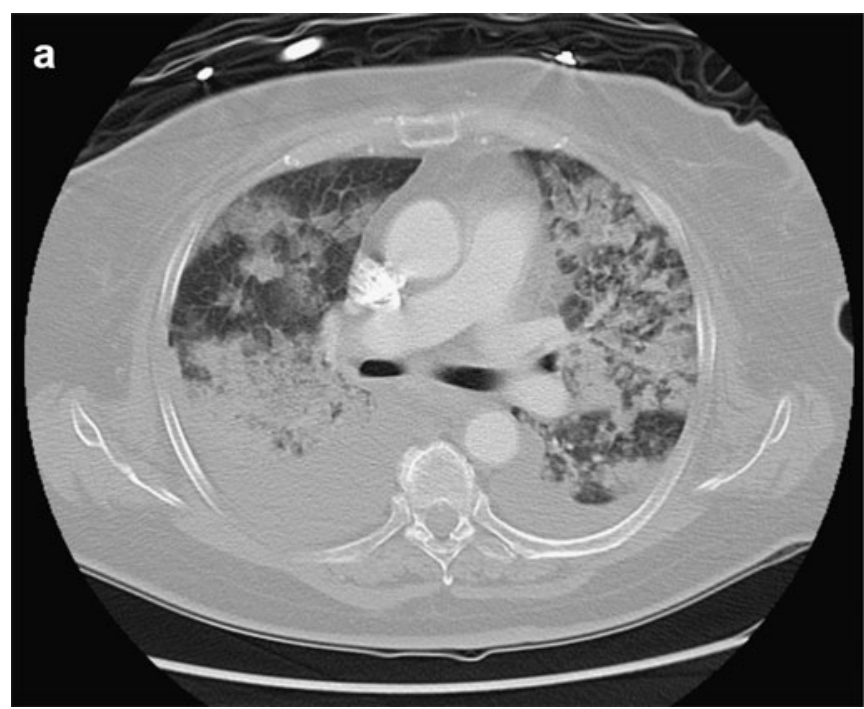

Fig. 1 Chest CT-scans of two European patients with hantavirus pulmonary syndrome. The examination showed pronounced diffuse bilateral interstitial infiltrates with pulmonary oedema, together with

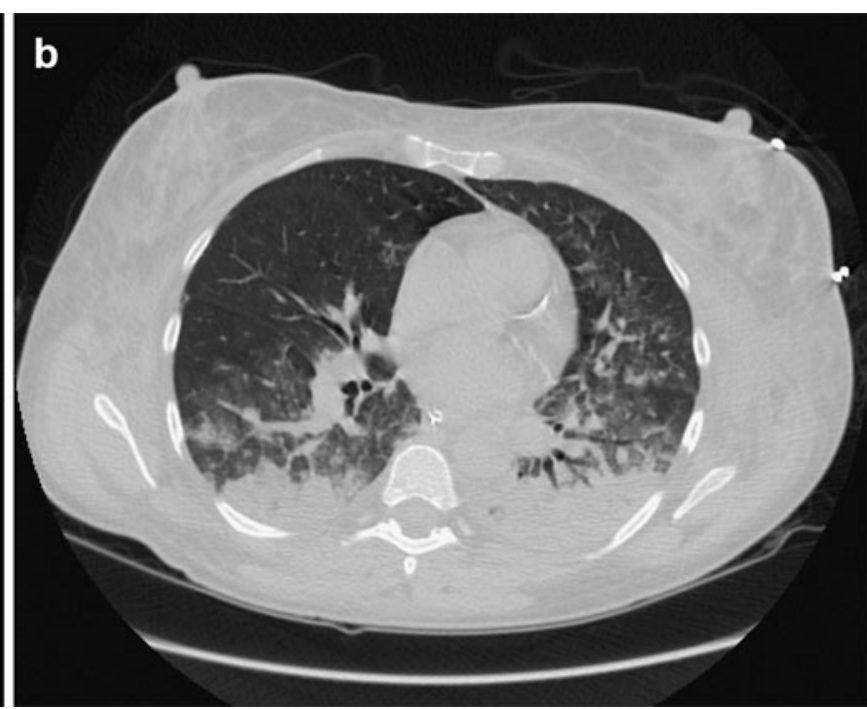

bilateral dependent atelectasis and moderate pleural effusions in patient 1 (a) and diffuse bilateral alveolar and interstitial infiltrates with dependent consolidation in patient 2 (b)
Autopsy revealed oedematous and atelectatic lungs with no normal aerated tissue. Pulmonary histopathological features consisted of diffusely oedematous parenchyma with interstitial and intraalveolar fibrosis. The alveoli contained exudates of fibrinous fluid, high number of alveolar macrophages $\left(\mathrm{CD}^{+} 8^{+}\right)$, proliferative epithelial cells and thick septa but without characteristic hyaline membranes. Interstitial mononuclear cell infiltrates were common, consisting mainly of $\mathrm{CD}^{+} \mathrm{T}$ lymphocytes whereof a vast majority was $\mathrm{CD} 8^{+}$. Many mononuclear cells were expressing cytotoxic markers granzyme $\mathrm{B}$ and $\mathrm{T}$ cell restricted intracellular antigen-1, TIA-1 (Fig. 2). In pulmonary vessels, focal thrombosis was evident. Microscopy of the heart showed thrombosis in small vessels and focal massive infiltrates of granulocytes and macrophages. In the brain there was focal vasculitis, perivascular infiltration of $\mathrm{CD}^{+} \mathrm{T}$ lymphocytes and non-occlusive thrombosis. Infarctions were seen in the brain, lungs and spleen. Notably, the kidneys had no prominent inflammatory infiltrates.

\section{Patient 2}

A 65-year-old woman was admitted to the ICU with acute respiratory distress and circulation insufficiency. Besides a history of Waldenstrom's macroglobulinemia that had not required active treatment, she had no history of health problems, infections or recent hospitalisations. She was a lifelong non-smoker, lived in a rural home with her husband, and handled firewood for home heating. Four days prior to admission the patient noted fever, chills, dyspnoea with dry cough and diarrhoea. On the day of admission, these symptoms were more severe, and an ambulance had been called because of syncope. Her ability to oxygenate deteriorated progressively during the first hospital day, and she was intubated and mechanically ventilated.

Chest X-ray on admission showed bilateral diffuse lung infiltrates and signs of interstitial oedema. Large bilateral pleural effusions were noted, and $>1000 \mathrm{ml}$ were drained. Echocardiographic examination identified normal left ventricular wall motion, and no signs of structural abnormalities or of pulmonary hypertension. Thin-cut CT images of the lungs on the third ICU day showed diffuse bilateral alveolar and interstitial infiltrates with dependent consolidation (Fig. 1). The clinical course during the first seven days was dominated by respiratory insufficiency requiring maximal ventilatory support with high levels of inspired oxygen, as well as circulatory shock requiring treatment with vasopressor and inotropic infusions. Other important clinical aspects included coagulopathy with diffusely spread petechiae, progression of renal failure with anuria requiring dialysis, and elevated levels of LDH (Table 1). She was treated presumptively for bacterial pneumonia and sepsis with a series of broad spectrum antibiotics and corticosteroids, without apparent response.

Hantavirus infection was verified with the detection of PUUV RNA in plasma $(630,000$ copies/ml) on the day of admission, while IgM and IgG were negative. Seroconversion with positive $\operatorname{IgM}$ and $\operatorname{IgG}$ occurred two and seven days later, respectively. Consecutive plasma samples were analysed for PUUV RNA with declining viral copy numbers until negative 16 days post onset of 

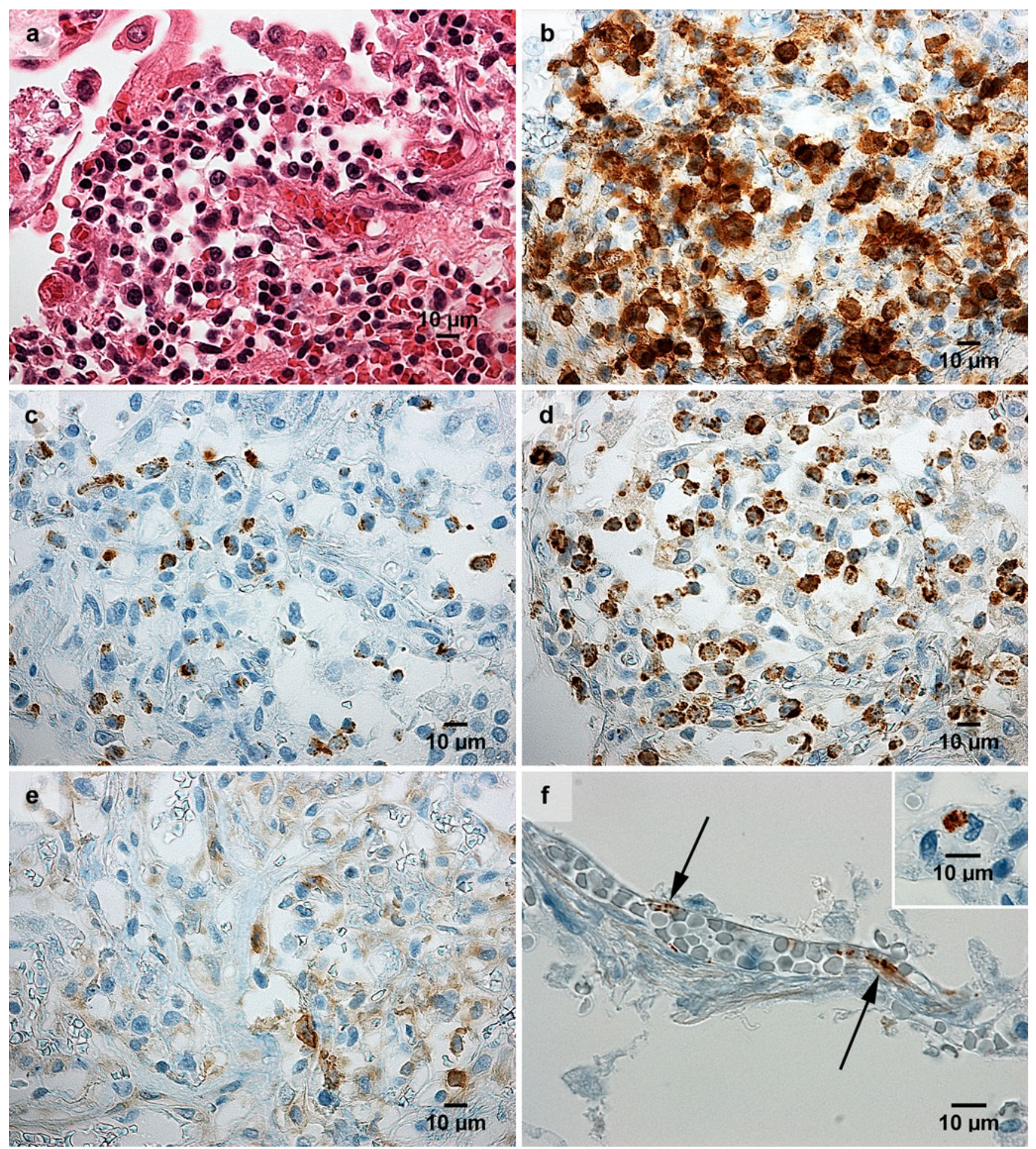

Fig. 2 Immunohistochemistry results in lung sections from two fatal cases of hantavirus pulmonary syndrome. The findings were condensed oedematous pulmonary parenchyma with alveolar fibrinous exudate and infiltrates of mononuclear cells (a), whereof a vast majority were $\mathrm{CD} 8^{+} \mathrm{T}$ lymphocytes (b), and many were holding granules containing granzyme B (c) and $\mathrm{T}$ cell restricted antigen-1, TIA-1 (d); this immunophenotype is characteristic of activated cytotoxic $\mathrm{T}$ lymphocytes. In contrast, $\mathrm{CD} 4^{+}$helper $\mathrm{T}$ lymphocytes (e) were uncommon. Viral antigen was detected in capillary vascular

endothelium (f) and in mononuclear cells, here represented by a monocyte (f; inset), using Puumala hantavirus nucleocapsid protein monoclonal antibody (A1C5, Progen Biotechnik GmbH, Heidelberg, Germany). For viral antigen, lung samples from two non-hantavirus patients were used as negative controls (data not shown). Panels (Patient 1 in a-e; original magnification, $\mathrm{x} 400$; and Patient 3 in $\mathbf{f}$; original magnification, $\mathrm{x} 600$ ) display lung sections from paraffin embedded material. Staining was performed using hematoxylin and eosin (a), and immunoperoxidase technique $(\mathbf{b}-\mathbf{f})$ 
disease (data not shown). PUUV RNA was found in bronchoalveolar lavage fluid $(11,000$ copies $/ \mathrm{ml})$ nine days after onset of disease. Bacterial cultures were all negative. The patient remained ventilator-dependent for 13 days, but was finally extubated. She developed critical illness myopathy and needed six weeks in-hospital rehabilitation. At follow-up six months later, she complained of muscle ache during exercise and lowered general fitness, but was steadily improving.

\section{Patient 3}

A 63-year-old male construction worker was admitted to the ICU with acute respiratory distress, confusion and hypotension. He was a current and long-time smoker with a medical history of mild chronic obstructive pulmonary disease and hypertension. Three days prior to admission he had fallen ill with fever, chills, diarrhoea, dry cough, and dyspnoea. In the emergency room, physical examination was notable for fever, somnolence, tachycardia and hypotension. Arterial blood gas analysis on room air revealed hypoxia and respiratory alkalosis. The patient was taken to the ICU and therapy was started with broad spectrum antibiotics due to suspicion of pneumonia and sepsis. As with the other patients, coagulopathy, increased LDH levels, and renal failure were detected (Table 1).

Initial bedside chest X-ray showed no findings to explain the respiratory distress. During the two days ICU course, the patient complained mostly of dyspnoea. He received supplemental oxygen and non-invasive ventilator support initially, but was eventually intubated and mechanically ventilated. CT findings which included only the lower lung lobes revealed bilateral pleural effusions and bibasilar atelectasis (data not shown). During the first day blood pressure was maintained with i.v. fluid, but on the second day his circulatory condition rapidly deteriorated. Despite massive efforts with i.v. fluid, corticosteroids and vasoactive drugs, the patient died in refractory circulatory shock.

PUUV serology on the first hospital day was $\operatorname{IgM}$ positive, while IgG was negative. The patient had 130,000 copies of PUUV RNA/ml in plasma. Bacterial cultures were all negative. At autopsy, PUUV RNA was detected in samples from lungs, heart, liver, kidney, brain and spleen. The organs were examined for viral antigen, which was found in the vascular endothelium and in mononuclear cells (Fig. 2).

Post mortem examination showed that pulmonary architecture was preserved but with oedema and focal non-occlusive thrombosis. Similar to patient 1 , there were pulmonary infiltrates of lymphocytes with the same immunophenotype as described (data not shown). Kidneys showed no prominent inflammation.

\section{Discussion}

Growing evidence show that there are similarities between HFRS and HPS, as both syndromes can give rise to hemorrhagia, renal impairment and cardiopulmonary dysfunction, which have been attributed to thrombocytopenia and capillary leakage $[1,3,8,9,11,20,21]$.

Severe pulmonary involvement has not been generally perceived to be a significant feature of HFRS. Previously, respiratory symptoms were commonly attributed to fluid overload as a result of renal failure. However, increasing evidence show that lung and heart involvement is common during the acute phase of HFRS [10, 11, 22, 23]. Concerning the cases of European hantavirus infection in our present report, there was only mild or no renal impairment at the time of admission, whereas the respiratory involvement was early and severe, consistent with acute respiratory distress syndrome (ARDS), fulfilling criteria of HPS according to CDC case definition [19]. As described in HPS, the three reported patients suffered from cardiovascular dysfunction, requiring treatment with inotropic and vasopressor drugs [9]. Autopsy results support the cause of death to be cardiopulmonary distress due to hantavirus infection. The lungs of both the deceased patients were oedematous and contained mononuclear cell infiltrates with predominantly $\mathrm{CD} 8^{+} \mathrm{T}$ lymphocytes, as described in HPS patients [2, 7]. Many cells expressed granzyme B and TIA-1, indicating a cytotoxic activity, which could further be supported by high levels of LDH. We chose to demonstrate the immune response in a non-smoker's lungs (patient 1), but a similar picture was seen in patient 3 .

In the first two patients, the IgM response was delayed, while the quantitative real-time RT-PCR for PUUV RNA was positive, suggesting it as a valuable tool to hasten the aetiological diagnosis [18]. Notably, in patient 1 PUUV RNA was found in serum from three weeks prior to the acute onset of disease, that is, in incubation phase and consistent with hantavirus incubation time ranging from one to four weeks $[3,24]$.

Pulmonary involvement is well documented in European Puumala hantavirus infection. From a single outbreak in our county, we report on three cases of life-threatening hantavirus pulmonary syndrome. Arguably, additional cases are likely to either go undiagnosed or unreported. A clinical implication of this observation is that hantavirus infection should be included as a differential diagnosis for patients with febrile illness and acute respiratory distress of uncertain cause in endemic areas in Eurasia.

Acknowledgements Irene Eriksson and Ingrid Gustafsson are greatly acknowledged for their skilled technical assistance. This work was supported with grants from the Swedish Heart Lung Foundation, the Heart Foundation of Northern Sweden, the County Councils of Northern Sweden, the County Council of Västerbotten, and the Medical Faculty of Umeå University. 
Conflict of interest The authors declare that they have no conflict of interest.

Open Access This article is distributed under the terms of the Creative Commons Attribution Noncommercial License which permits any noncommercial use, distribution, and reproduction in any medium, provided the original author(s) and source are credited.

\section{References}

1. Duchin JS, Koster FT, Peters CJ, Simpson GL, Tempest B, Zaki SR, Ksiazek TG, Rollin PE, Nichol S, Umland ET et al (1994) Hantavirus pulmonary syndrome: a clinical description of 17 patients with a newly recognized disease. The hantavirus study group. N Engl J Med 330(14):949-955

2. Nolte KB, Feddersen RM, Foucar K, Zaki SR, Koster FT, Madar D, Merlin TL, McFeeley PJ, Umland ET, Zumwalt RE (1995) Hantavirus pulmonary syndrome in the United States: a pathological description of a disease caused by a new agent. Hum Pathol 26(1):110-120

3. Vapalahti O, Mustonen J, Lundkvist A, Henttonen H, Plyusnin A, Vaheri A (2003) Hantavirus infections in Europe. Lancet Infect Dis 3(10):653-661

4. Botten J, Mirowsky K, Ye C, Gottlieb K, Saavedra M, Ponce L, Hjelle B (2002) Shedding and intracage transmission of Sin Nombre hantavirus in the deer mouse (Peromyscus maniculatus) model. J Virol 76(15):7587-7594

5. Hardestam J, Karlsson M, Falk KI, Olsson G, Klingström J, Lundkvist A (2008) Puumala hantavirus excretion kinetics in bank voles (Myodes glareolus). Emerg Infect Dis 14(8):1209-1215

6. Linderholm M, Bjermer L, Juto P, Roos G, Sandström T, Settergren B, Tärnvik A (1993) Local host response in the lower respiratory tract in nephropathia epidemica. Scand J Infect Dis 25 (5):639-646

7. Zaki SR, Greer PW, Coffield LM, Goldsmith CS, Nolte KB, Foucar K, Feddersen RM, Zumwalt RE, Miller GL, Khan AS et al (1995) Hantavirus pulmonary syndrome. Pathogenesis of an emerging infectious disease. Am J Pathol 146(3):552-579

8. Mackow ER, Gavrilovskaya IN (2009) Hantavirus regulation of endothelial cell functions. Thromb Haemost 102(6):1030-1041

9. Saggioro FP, Rossi MA, Duarte MI, Martin CC, Alves VA, Moreli ML, Figueiredo LT, Moreira JE, Borges AA, Neder L (2007) Hantavirus infection induces a typical myocarditis that may be responsible for myocardial depression and shock in hantavirus pulmonary syndrome. J Infect Dis 195(10):1541-1549

10. Linderholm M, Billström A, Settergren B, Tärnvik A (1992) Pulmonary involvement in nephropathia epidemica as demonstrated by computed tomography. Infection 20(5):263-266

11. Linderholm M, Sandström T, Rinnström O, Groth S, Blomberg A, Tärnvik A (1997) Impaired pulmonary function in patients with hemorrhagic fever with renal syndrome. Clin Infect Dis 25 (5):1084-1089

12. Kanerva M, Paakkala A, Mustonen J, Paakkala T, Lahtela J, Pasternack A (1996) Pulmonary involvement in nephropathia epidemica: radiological findings and their clinical correlations. Clin Nephrol 46(6):369-378

13. Clement J, Colson P, McKenna P (1994) Hantavirus pulmonary syndrome in New England and Europe. N Engl J Med 331 (8):545-546, author reply 547-548

14. Caramello P, Canta F, Bonino L, Moiraghi C, Navone F, Lipani F, Balbiano R, Caputo AM, Gai V (2002) Puumala virus pulmonary syndrome in a Romanian immigrant. J Travel Med 9(6):326-329

15. Hoier S, Aberle SW, Langner C, Schnedl W, Hogenauer C, Reisinger EC, Krejs GJ, Krause R (2006) Puumala virus RNA in patient with multiorgan failure. Emerg Infect Dis 12(2):356-357

16. Seitsonen E, Hynninen M, Kolho E, Kallio-Kokko H, Pettila V (2006) Corticosteroids combined with continuous veno-venous hemodiafiltration for treatment of hantavirus pulmonary syndrome caused by Puumala virus infection. Eur J Clin Microbiol Infect Dis 25(4):261-266

17. Pettersson L, Boman J, Juto P, Evander M, Ahlm C (2008) Outbreak of Puumala virus infection, Sweden. Emerg Infect Dis 14(5):808-810

18. Evander M, Eriksson I, Pettersson L, Juto P, Ahlm C, Olsson GE, Bucht G, Allard A (2007) Puumala hantavirus viremia diagnosed by real-time reverse transcriptase PCR using samples from patients with hemorrhagic fever and renal syndrome. J Clin Microbiol 45(8):2491-2497

19. CDC (2010) Hantavirus pulmonary syndrome, 2010 case definition. Atlanta: Centers for Disease Control and Prevention (CDC). Available at http://www.cdc.gov/ncphi/disss/nndss/casedef/ hantaviruscurrent.htm. Accessed on 1 September 2010

20. Peters CJ, Khan AS (2002) Hantavirus pulmonary syndrome: the new American hemorrhagic fever. Clin Infect Dis 34(9):1224-1231

21. Bayard V, Kitsutani PT, Barria EO, Ruedas LA, Tinnin DS, Munoz C, de Mosca IB, Guerrero G, Kant R, Garcia A, Caceres L, Gracio FG, Quiroz E, de Castillo Z, Armien B, Libel M, Mills JN, Khan AS, Nichol ST, Rollin PE, Ksiazek TG, Peters CJ (2004) Outbreak of hantavirus pulmonary syndrome, Los Santos, Panama, 1999-2000. Emerg Infect Dis 10(9):1635-1642

22. Puljiz I, Kuzman I, Markotic A, Turcinov D, Matic M, Makek N (2005) Electrocardiographic changes in patients with haemorrhagic fever with renal syndrome. Scand J Infect Dis 37(8):594-598

23. Mäkelä S, Kokkonen L, Ala-Houhala I, Groundstroem K, Harmoinen A, Huhtala H, Hurme M, Paakkala A, Pörsti I, Virtanen V, Vaheri A, Mustonen J (2009) More than half of the patients with acute Puumala hantavirus infection have abnormal cardiac findings. Scand J Infect Dis 41(1):57-62

24. Ferres M, Vial P, Marco C, Yanez L, Godoy P, Castillo C, Hjelle B, Delgado I, Lee SJ, Mertz GJ (2007) Prospective evaluation of household contacts of persons with hantavirus cardiopulmonary syndrome in Chile. J Infect Dis 195(11):1563-1571 